\title{
Factors Hindering the Adoption of Business-to-Consumer (B2C) in Developing Countries: A Case Study
} of Sudan

\author{
Abdelaziz Musbah, Mira Kartiwi \\ International Islamic University Malaysia, Malaysia \\ amus2007@yahoo.com,arrairy@gmail.com
}

\begin{abstract}
It has been commonly reported that e-commerce (electronic commerce) offers viable solutions to businesses in meeting the challenges of an environment that is undergoing changes. This study seeks to explore the factors that influence the adoption decision of Business-to-Consumer (B2C) e-commerce, using Sudan as a case study. The mixed method design was adopted in two stages in which both exploratory and descriptive research approaches were undertaken. Data was collected from enterprises by questionnaire and through the analysis of research and semi-structured interviews. The findings revealed that most enterprises in the country are still in the initial stages of adoption of B2C e-commerce despite the wide growth of Internet use among enterprises in Sudan. Many factors could be responsible for the low usage of e-commerce among the enterprises in Sudan. Technical barrier is seen as the major barrier that affects the adoption of B2C e-commerce. However, this is accompanied by regulatory and legal barriers. One of the factors that inhibit e-commerce adoption in SMEs in Sudan is the lack of Internet security. Other factors include limited use of web portals and Internet banking by enterprises. The use of credit card and visa card is prohibited in Sudan due to the sanction from the United States of America. However, these issues resulted in all type of transactions that involves carrying cash. This makes it risky for customer who carry huge sum of money. In order to improve B2C e-commerce adoption technologies, this study plays a significant role to organizations and supporting organizations, especially those operating in countries with a unique situation like Sudan.
\end{abstract}

\section{Keywords: Business-to-Consumer (B2C), Developing countries, E-Commerce Factors, Sudan}

\section{Introduction}

Business-to-consumer usually has a major focus on business transactions that takes place between businesses and consumers (Duncombe \& Heeks, 2001). Despite the benefits and rapid growth of e-commerce, it has been indicated that only large organizations have obtained the benefits of e-commerce (MacGregor \& Kartiwi, 2010; MacGregor \& Vrazalic, 2005; Riquelme, 2002); though SMEs being at a low level relatively. Consequently, this situation is common in many developing countries (Kapurubandara \& Lawson, 2006). There has been a continuous steady growth in B2C e-commerce, despite the dot-com failures in 2000s (Van Slyke et al., 2004). This growth took place in both developed and developing countries, resulting in a community of more comprehensive online buyers (Cyr et al., 2004). Some studies stated that consumers are not willing to involve themselves in e-commerce activities which relates to cost, security, and privacy concerns (Azam \& Shah, 2007). In particular, the study has four objectives in exploring and describing. These factors are: (1) Factors affecting the adoption of B2C e-commerce by organizations in Sudan, (2) The impact of political and economic conditions, and government policies on B2C e-commerce growth among organizations in Sudan, (3) The current e-commerce adoption level for organizations in Sudan, and (4) Organizations perception of B2C e-commerce implementation and adoption. The factors that affect e-commerce adoption of an organization in developing countries play a significant role to the organization, the public, as well as the government. Organizations can consider the most effective means of utilizing the advantages of e-commerce in improving their business efficiency and in promoting the growth of their business. The proposed research exposes some of the problems of various policies in government. The research also suggests possible solutions for the policies to meet the requirement of the businesses and whether it is feasible and implementable on the ground.

Aims and objectives: This study aims to develop a framework, and identifies the factors affecting Business-to-Consumer (B2C) e-commerce in Sudan. The objectives of this study include: to explore the major barriers that affects Business-to-Consumer (B2C) adoption; to perform an in-depth investigation on factors that affects B2C adoption in Sudan; to develop the framework for adoption of B2C e-commerce in Sudan; to make specific recommendations in eliminating the problems affecting B2C adoption in Sudan; and to validate the framework. 


\section{Research Questions}

What are the factors that affect the B2C e-commerce adoption by SMEs in Sudan?

To facilitate a detailed exploration of the overall research question, the question was divided into manageable questions as follows:

- What are the key factors affecting B2C e-commerce adoption by SMEs in Sudan?

- How have government policies, economic, and political conditions affected B2C e-commerce growth in SMEs?

- What is the e-commerce adoption level for SMEs in Sudan?

- What perception does SMEs in Sudan have towards B2C e-commerce?

- What factors drive SMEs in Sudan into e-commerce adoption?

\section{Literature Review}

Critical Success Factors (CSFs): According to Collis and Hussey (2003), a theoretical framework involves the process of obtaining models and theories from study findings. Consequently, it is regarded as a basic part of positivist research since it addresses both the research questions and hypotheses. In this paper, the factors identified through the literature review and how this would affect the implementation of E-commerce creates the theoretical framework as follows:

Environmental Context: Environmental factors have a significant effect on online environment and e-commerce activities. As a result, it affects businesses in general and customers in particular. However, the most highlighted issues include:

ICT Infrastructure: Tangpong et al. (2009) stated that the availability of technological infrastructure is the key to the e-commerce adoption. In Sudan, there is poor or unreliable internet connectivity which is attributable to epileptic power supply and poor telephone communication (Lawrence \& Tar, 2010). In ICT, Sudan has made enormous progress in liberalizing the sector. Due to this progress, it has attracted significant private capital. Recently, connectivity to an undersea fiber-optic cable has led to expansions for accessibility, price reduction, and quality improvements (Rupa \& Cecilia, 2011). Sudan, in recent decades, has built and benefited from ICT. Development of ICT in Sudan is evident in a major expansion of the infrastructure and capital investment, including systems and human capital management (Elamin, 2004).

Public Awareness: Hunaiti, Masa'deh, Mansour and Al-Nawafleh (2009) identified that unawareness among individuals as a major factor which hinders e-commerce adoption. They stated the importance for individuals to have access to services at the same time, and knowing how to use them.

Economic and Political Conditions: The economic condition of a place is a major drive for the adoption of e-commerce (Lawrence \& Tar, 2010; Molla, 2005). Furthermore, it was argued by Lawrence and Tar (2010) that the establishment of technology infrastructure in most developing countries exceeds their ability by far. Hence, the growth of e-commerce in countries with unfavorable economic conditions is slow relatively (Lawrence \& Tar, 2010). The unstable economic condition of some countries affects their involvements in the development of ICT (Matula \& Van Brakel, 2007).

Government Initiatives, Legislation, and Support: The role of government in providing various forms of intervention has been cited as a catalyst for SMEs e-commerce development (Southern \& Tilley, 2000; Sarosa \& Zowghi, 2003; Thatcher et al., 2006; Martinsons, 2008). Researchers (Dunt \& Harper, 2002; Chan \& Al-Hawamdeh, 2002; Martinsons, 2008) noted that the developed countries' ability to adopt and use e-commerce and e-business at advanced levels has been greatly enhanced by their government's proactive role in providing the enabling infrastructure for e-commerce to thrive. This is often lacking in developing countries, as their governments are concern with issues of poverty and hunger eradication (OECD, 2004). Chan and Al Hawamdeh (2002) provide an example of the role of government in the development of e-commerce in Singapore where deliberate steps have been taken to improve e-commerce infrastructure by enacting favorable e-commerce laws. Unfavorable government and regional policies stifle creativity among SMEs, threatening the existence of this sector in the economy. 
Logistics Infrastructure: Fast development and growth of e-commerce in the US can be a result of infrastructure already in place. It can also occur due to a physical delivery method that is easily available. Such systems are less in developing countries (Hawk, 2004). One of the key for e-commerce is a logistic infrastructure that is effective. In Sudan, the absence of mailboxes for homes serves as a limitation to retailing online. A delivery method of products to housing location is supported through the provision of the appropriate infrastructure required.

Organizational Context: Organizational factors are defined from the nature and characteristic of the firm itself, usually making it unique to the firm. Cloete (2002) and Cloete et al. (2001) stated that the organizational factors which affects the adoption and implementation of e-commerce include; the inability to have access to hardware and software, inadequate time to scrutinize information and options, poor knowledge about the methodologies and models of e-commerce, and poor accessibility to computers. The factors were classified into the characteristics of owner/manager, firm's characteristics, and the poor access to financial resources.

Owner/Manager Characteristics: Most factors that hinder e-commerce adoption in organizations are related to the characteristics of the owners/managers (Kapurubandara \& Lawson, 2006; Kirby \& Turner, 1993). There is a lack of awareness of the potential benefits of e-commerce adoption by business owners (Lacovou, Benbasat \& Dexter, 1995). They mostly do not understand and appreciate the potential benefits of adopting e-commerce services (Kapurubandara \& Lawson, 2006); therefore, they less likely adopt e-commerce for lack of knowledge or ignorance on the use of computer technology (Cloete, Courtney \& Fintz, 2002; Kapurubandara \& Lawson, 2006; Kirby \& Turner, 1993; Lacovou et al., 1995; Matula \& Van Brackel, 2007).

Firm Characteristics: There are a number of factors which affect e-commerce adoption by the organizations. In an organization, the amount of technology presently being used in an organization, such as PCs with modems and the use of e-mails, can make adoption easier (Lacovou et al., 1995). The determinant criteria as to whether or not e-commerce services will be adopted by an organization has a great impact on whether or not an organization will adopt e-commerce services.

Financial Infrastructure: Graham and Cobham (2006) stated that the top management's willingness to fund an e-commerce adoption project is a clear reflection of financial readiness. Therefore, the major cost for the adoption of e-commerce involves the training and educating of employees/management on the use/application of e-commerce (Graham \& Cobham, 2006). According to Nelson and Shaw (2003), the rate of e-commerce adoption is affected by financial feasibility. Some examples of innovations which affect consumers are debit and credit cards, e-banking, automated teller machines (ATMs), and stored value cards. Furthermore, innovations which promote online commerce include encrypted credit cards, smart cards, e-cash, and e-checks. In developing countries, these methods of payment are very common. In particular, because of US laws and regulations, credit cards are generally not allowed to be used in prohibited countries, including Iran, Burma (Myanmar), Sudan, and Cuba. Hence, the only exception is Diners Club, which is accepted by the Khartoum Hilton. All transactions have to be in cash, making it unsafe for visitor carrying large sums of money with him.

Lack of Credit Cards and Payment Systems: In transactions between consumers and SMEs (also known as C2B), the lack of ownership of credit cards in Southern Africa has prevented many people from participating in e-commerce activities (Shemi \& Magembe, 2002). Some organizations have also been prevented from advancing to e-payment operations due to lack of appropriate e-commerce payment systems.

Lack of Financial Resources: Among the many challenges that hinder development of e-commerce in firms is the issue of finance as it relates to the amount of financial resource utilized by an enterprise to start up, buy the necessary ICT infrastructure for the implementation of e-commerce, paying consultancy fees and training personnel, and maintenance of websites and other infrastructure (Mutula \& Van Brakel, 2007; Lee et al., 2003; Sarosa \& Zowghi, 2003). According to Kauffmann (2005), the growth of SMEs in Africa is hampered by their limited access to finances. Furthermore, their security is not sure; unpredictable; and due to their sectoral and regional focus, they have few risks scope of sharing. 
Technological Context: In most developing countries, slow speed of telecommunication networks and the lack of Internet connectivity have greatly contributed to the delay in e-commerce adoption (Mutula \& Van Brakel, 2007). Despite the availability of Internet connectivity, its continued use in SMEs is hampered by epileptic power supply, commonly in the rural areas of the country (Mutula \& Van Brakel, 2007). Among managers, there is a general fear that e-commerce and ICTs are both a complex phenomenon (Magembe \& Shemi, 2002). Perceived benefits possess a significant factor that affects the several studies adoption (Iacovou et al., 1995; Kuan \& Chau, 2001; Rogers, 1995). Thus, perceived benefits include both indirect and direct benefits. Therefore, these benefits are gotten from the adoption of technology. If the management of an organization have good understanding of the various benefits and if it does not perceive the technological innovation in a positive way, then the organization is less likely to adopt the technology in a method that is active (Iacovou et al., 1995; Kirby \& Turner, 1993). Furthermore, in any online transactions, risks and security is considered as a very important factor which determines the level of the adoption of e-commerce.

Concerns on Trust, Confidentiality, and Security: The term "trust" can be referred to as a major determinant in e-commerce adoption. When compared with tradition commerce, they opined that in e-commerce, it is not easy to establish trust between partners. Based on the fact that online products and services are not easily verified, trust is considered to be more important in e-commerce than in traditional commerce services (Gefen \& Straubb, 2004; Lawrence \& Tar, 2010). Lawrence and Tar (2010) opined that "confidence and trust are essential requirements to secure electronic trading" (p. 28). Also, more time should be allocated to promoting confidence in electronic transactions in order to expand the digital economy. They should be assurance that shoppers will receive the goods or services they have placed order for; their personal data are well protected; and they have a secured means of communications (Kirby \& Turner, 1993). In addition, this growth has to do with the use of secured and reliable payment method to avoid illegal actions and other fraudulent practices (Mohamad \& Ismail, 2009).

\section{Methodology}

In Sudan, an exploratory mixed method design was adopted in two stages, both exploratory and descriptive research approaches. This was done as a result of the absence of empirical studies on B2C e-commerce. The first stage, which was intended for theory generation, adopted an exploratory research design where qualitative data were collected to clarify problems. This stage provides information on the adoption of e-commerce as opined by the enterprise. In addition, it is used to construct a research questionnaire for the following stage. The second stage adopted a descriptive design research for measuring and describing various subject areas. Empirical data in the form of survey research were gathered and used in the second stage to validate and determine the direction of the variable relationships. From previous studies, a theoretical framework was drawn, which will be investigated in the case study organization. Subsequently, the author expects to incorporate the findings from case studies into existing theory.

\section{Findings and Discussion}

The study looked at barriers affecting the adoption of B2C e-commerce by organizations in Sudan. It attempted to analyze the various factors, which that affects B2C e-commerce adoption and implementation. The study findings show failure and delay in the adoption of B2C e-commerce by organizations in Sudan. Despite the evidence of a large growth of the Internet among organizations in the country, very few of them are fully utilizing B2C e-commerce services. In fact, most organizations are at the primary stages of the adoption of e-commerce. A lot of barriers which lead to a slow diffusion of B2C e-commerce among organizations in the country was identified in this study. Thus, it underlies inhibitors such as poor public awareness, epileptic power supply, poor technological infrastructure etc. Due to weak technological infrastructure in the country, the network has a limited coverage, very unreliable, and very slow. In addition, the lack of funds has also led to regular power cuts and it limits the use of technological equipment. Not only that, but also, the embargo of US and the West limit the payment online. Subsequently, poor economy occurs as a result of poor awareness by the public. Further to this, organizations experienced financial challenges for technological initiation. Unawareness was identified as another inhibitor of B2C e-commerce adoption by organizations in Sudan. In addition, the findings of this research show that both organizations and customers are concerned with the information confidentiality and security online. In conclusion, the government in 
Sudan and well-meaning organizations plays a vital function in creating an environment that is conducive to the adoption of B2C e-commerce. In addition, technological facilities should be provided by the government. In addition, this would later make the ICT network to be readily available and easily affordable.

Future work: Further research needs to be carried out in the areas below:

- In Sudan, e-commerce is in the foundation stage. In addition, this leads to a rapid change in technology and other issues which might not be observed in this study.

- M-commerce has been proposed as a solution for developing countries in adopting e-commerce. A future study could be carried out on M-commerce in African countries in particular, especially after the launch of the African Telecommunication Satellite.

\section{Reference}

Azam, M. D. \& Shah, N. (2007). Implementation of B2C e-commerce in Bangladesh: The effects of buying culture and e-infrastructure. Advances in Global Business Research, 3(1), 55-81.

Chan, B. \& Al-Hawamdeh, S. (2002). The development of e-commerce in Singapore: The impact of government initiatives. Business Process Management Journal, 8(3), 278 - 288.

Chen, S. \& Ning, J. (2002). Constraints on E-Commerce in less developed countries: the case of China. Electronic Commerce Research, 2, 31-42.

Cloete, E., Courtney, S. \& Fintz, J. (2002). Small business' acceptance and adoption of e-commerce in the Western-Cape Province of South Africa. Electronic Journal on Information Systems in Developing Countries, 10(4), 1-13. Retrieved January 5, 2014, from http://www.ejisdc.org.

Collis, J. \& Hussey, R. (2003), Business research a practical guide for undergraduate and postgraduate students. Palgrave Macmillan.

Cyr, D., Bonanni, C. \& Ilsever, J. (2004). Design and e-Loyalty across Cultures in Electronic Commerce, Proceedings of the 6th International Conference on Electronic Commerce, 2004. Delft: Netherlands, pp 351-360.

Duncombe, R. \& Heeks, R. (2001). Information and communication technologies (ICTs) and small enterprise in Africa. $\quad$ Retrieved April 13, 2015, from http://www.sed.manchester.ac.uk/idpm/research/is/ictsme/index.htm.

Dunt, E. S. \& Harper, I. R. (2002). E-commerce and the Australian Economy. The economic record, 78, 242, 327-342.

Elamin, A. (2004). K. Promoting ICT for Human Development in Sudan. ICS Portal for Technology Transfer.

Gefen, D. \& Straubb, D. W. (2004). Consumer trust in B2C e-commerce and the importance of social presence: Experiments in e-products and e-services. International Journal of Management Science, 32(6), 407-424.

Hawk, S. (2004). A comparison of B2C e-commerce in developing countries. Electronic Commerce Research, 4 , 181-199.

http://wikitravel.org/en/Wikitravel:Travellers'_pub/2013.

Hunaiti, Z., Masa'deh, R., Mansour, M. \& Al-Nawafleh, A. (2009). Electronic commerce adoption barriers in small and medium-sized enterprises (SMEs) in developing countries: The case of Libya. IBIMA Business Review, 2(5), 37-45.

Kapurubandara, M. \& Lawson, R. (2006). Barriers to adopting ICT and e-commerce with SMEs in developing countries: An exploratory study in Sri Lanka. Proceedings of the Conference on Collaborative Electronic Commerce Technology and Research, 9 December 2006 (pp. 1-13) Adelaide.

Kauffmann, C. (2005). Financing SMEs in Africa. Policy Insights, 7, 1-4. Retrieved May 10, 2013, from http://www.oecd.org/dataoecd/57/59/34908457.pdf.

Kirby, D. \& Turner, M. (1993) IT and the small retail business. International Journal of Retail and Distribution Management, 21(7), 20-27.

Kuan, K. \& Chau, P. (2001). A perception-based model of EDI adoption in small businesses using technology-organization-environment framework. Information and Management, 38, 507-521.

Lacovou, C. L., Benbasat, I. \& Dexter, A. A. (1995). Electronic data interchange and small organizations: Adoption and impact of technology. MIS Quarterly, 19(4), 465-485. 
Lawrence, J. E. \& Tar, U. A. (2010). Barriers to ecommerce in developing countries. Information, Society and Justice, 3(1), 23-35. Retrieved August 20, 2015, from http://www.londonmet.ac.uk/fms/MRSite/acad/dass/ISJ\%20Journal/V3N1/03_Barriers\%20to\%20 E-commerce\%20in\%20developing\%20countries_Lawrence\&Tar.pdf.

MacGregor, R. C. \& Kartiwi, M. (2010). Perception of barriers toe-commerce adoption in SMEs in a developed and developing country: A comparison between Australia and Indonesia. Journal of Electronic Commerce in Organizations, 8(1), 61-82. Retrieved September 18, 2013, from http://www.igi-global.com/viewtitlesample.aspx?id=40249.

MacGregor, R. \& Vrazalic, L. (2005). A basic model of electronic commerce adoption barriers: A study of regional businesses in Sweden and Australia. Journal of Small Business and Enterprise Development, $12(4), 510-527$.

Martinsons, M. G. (2008). Relationship-based e-commerce: theory and evidence from China. Information Systems Journal, 18, 331-356.

Matula, S. \& Van Brackel, P. (2007). ICT skills readiness for the emerging global digital economy among small businesses in developing countries: A case study of Botswana. Library High Tech, 25(2), 231-245.

Mohamad, R. \& Ismail, N. A. (2009). Electronic commerce adoption in SME: The trend of prior studies. Journal of Internet Banking and Commerce, 14(2), 1-16. Retrieved December 20, 2013, from http://www.arraydev.com/commerce/jibc/.

Molla, A. (2005). Exploring the Reality of ecommerce Benefits Among Businesses in a Developing Country, University of Manchester, Precinct Centre, Manchester, 2005, UK, available at: URL: http://www.sed.manchester.ac.uk/idpm/publications/wp/di/index.htm.

Mutula, S. M. \& van Brakel, P. (2007). E-readiness of SMEs in the ICT sector in Botswana with respect to information access. Electronic library, 24(3), 402-417.

Nelson, M. J. \& Shaw, M. L. (2003). The Adoption and Diffusion of Interorganizational Systems Standards and Process Innovation. J. Comput. Inf. Syst., 41(3), 70-73.

OECD. (2004). ICT, E-Business and SMEs, Organisation for Economic Co-Operation and Development, Retrieved 04 October 2014, from http://www.oecd.org/dataoecd/32/28/34228733.pdf.

Riquelme, H. (2002). Commercial Internet adoption in China: Comparing the experience of small, medium and large businesses. Internet Research: Electronic Networking Applications and Policy, 12(3), 276-286.

Rogers. (1995). Diffusion of Innovations. Free Press, New York.

Rupa \& Cecilia. (2011). The World Bank Africa Region Sustainable Development Unit September 2011, Sudan's Infrastructure a Continental Perspective Rupa Ranganathan and Cecilia M. Briceño-Garmendia.

Sarosa, S. \& Zowghi, D. (2003). Strategy for Adopting Information Technology for SMEs: Experience in Adopting Email within an Indonesian Furniture Company. Electronic Journal of Information Systems Evaluation, 6(2), 165-17.

Shemi, A. P. \& Magembe, B. A. S. (2002). Challenges and opportunities for adopting Electronic Commerce in a developing country: The Botswana Perspective, in Muuka, G. N. (ed.) (2002) IAABD Conference Proceedings, Port Elizabeth, 174-180.

Southern, A. \& Tilley, F. (2000). Small firms and information and communication technologies (ICT): Toward a typology of ICT usage. New Technology Work and Employment, 15(2), 138154.

Tangpong, C., Islam, M. \& Lertpittayapoom, N. (2009). New niche formation and creative destruction of B2C e-commerce: A multi-retail sector study. Proceedings of the 51st Annual Meeting of the Midwest Academy of Management (Strategy \& Organization Theory Track), (pp. 1-15).

Thatcher, S. M. B., Foster, W. \& Zhu, L. (2006). B2B e-commerce adoption decisions in Taiwan. Electronic Commerce Research and Applications, 5, 92-104.

Van Slyke, C., Belanger, F. \& Comunale, C. (2004). Factors Influencing the Adoption of Web-Based Shopping: The Impact of Trust. DATA BASE for Advances in Information Systems, 35(2), 32-49. 